\title{
Prognosis of ischemic stroke patients with or without collateralization after carotid stenosis
}

\author{
Subash Kanti Dey, Md. Shahidullah, Anis Ahmed, Ahsan Habib and Abu Nasar Rizvi
}

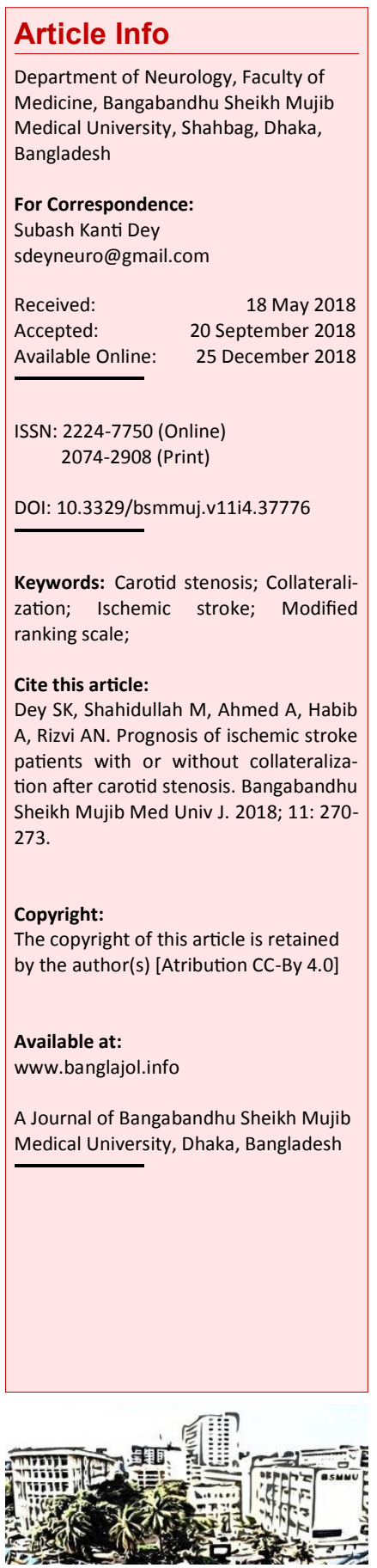

\section{Abstract}

The objective of this study was to see the association of the prognosis of ischemic stroke patients with or without collateralization after carotid stenosis. This study was conducted on 36 patients presenting with acute ischemic stroke who were going through digital subtraction angiography from March 2017 to March 2018. Collateralization status after unilateral or bilateral stenosis was evaluated. Modified ranking scale (mRS) score was measured on the first day of the stroke and after three months. The disability of ischemic stroke patients was compared between patients who developed collateralization and who had not. Among them, 61.6\% developed collateralization. Among the patients who developed collateralization after three months, $90.9 \%$ patients had $\mathrm{mRS}$ scale of $\leq 2$ and who not developed collateralization, $85.7 \%$ patients had mRS scale of $\leq 2$. In both the groups, the $\mathrm{p}$ value was $<0.05$. It can be concluded that carotid stenosed patients who suffered from ischemic stroke, most of the patients disability improved to some extents whether collateralization developed or not among the major vessels.

\section{Introduction}

The cerebral blood flow is supplied through the left and right internal carotid artery and basilar artery to the arterial circle of Willis, and thence to the brain. The collateral potential of the circle of Willis is believed to be dependent on the presence and size of its component vessels. 1

If internal carotid artery in one side is stenosed, the circle of Willis may allow the supply of blood from the contralateral carotid artery or the basilar artery to the territory of the stenotic internal carotid artery.? Impaired blood supply to the brain due to internal carotid artery obstructive disease is compensated by redistributing blood through the components of the arterial circle to maintain hemispheric circulation through the arteries emanating from the circle. The potential to develop these anterior and posterior collateral pathways depends on the continuity of the anterior and posterolateral parts of the circle of Willis, respectively. Collateral flow via the circle of Willis can be provided anteriorly via the right and left precommunicating anterior cerebral arteries (A1 segment) and the anterior communicating artery, and posteriorly via the ipsilateral posterior communicating artery and precommunicating posterior cerebral artery (P1 segment).

The size and patency of the arteries of the circle of Willis are variable. $\underline{3}$ Substantial individual differences in the anatomy of the circle of Willis of healthy subjects have been described. 4 Carotid atherosclerosis is a prominent cause of stroke in various populations around the world and noted as the most common vascular lesion in stroke patients. $.5,6$

After stroke, the survival of carotid stenosis patient depends on the quality of residual collateral blood supply. - Carotid atherosclerosis may incite downstream ischemia in a specific arterial territory due to hypoperfusion, in situ thrombosis, artery to artery emboli, perforator vessel occlusion by the atherosclerotic plaque, or combined mechanisms. 8 Collateral circulation may be beneficial by different pathophysiologic mechanisms, by sustaining downstream perfusion or enhancing embolic washout in distal arteries, although such influence may be diminished in perforator occlusion. $.9,10$ Predictors of stroke in this condition may also be explained by perfusion and the role of collaterals. Angiographic details such as the relative length and exact percentage of luminal stenosis may impact distal flow and therefore be related to collateral status. Systemic blood pressure may be related to collateralization or arteriogenesis and may also be linked with perfusion of the vascular territory.11 Even when the recurrent stroke occurs, collateral status may influence the resultant infarct size and clinical severity. 12

Ischemic stroke outcome varies considerably, 
from complete recovery to complete loss of tissue and function. This diversity is partly explained by the compensatory ability of the collateral circulation and the ensuing cerebral blood flow. $\underline{13}$ The collaterals are the pial arterioles connecting two major cerebral arteries that supply two different vascular territories. These arteriolar connections contribute to the retrograde filling of pial arteries distal to an occlusion, and they provide alternative routes for blood flow in the setting of acute ischemic stroke. There is a wide interindividual variability in the size, number, and localization of the collaterals. $\underline{14}$ Recent evidence suggests that these collaterals are dynamic, with a time-dependent recruitment of flow to the symptomatic hemisphere, once major occlusion has occurred. $\underline{15}$ Although conventional angiography is considered the gold standard for the collateral flow assessment, $\underline{16,17}$ there is wide variation in how leptomeningeal collateral grade is graded $18-20$ variables beyond a single measure of percent stenosis and the influence of collateral flow on stroke risk have not been explored. The association of collateral flow with hemodynamic variables and subsequent infarct size or stroke severity are also unknown. We, therefore, studied the potential impact of such extensive variability in collateral status on modifying the stroke risk due to intracranial atherosclerosis and the possible influen-

\begin{tabular}{|c|c|c|c|}
\hline \multicolumn{4}{|c|}{ Table I } \\
\hline \multicolumn{4}{|c|}{ Distribution of age and comorbidity by collateralization } \\
\hline & \multicolumn{2}{|c|}{ Collateralization } & \multirow{2}{*}{$\mathrm{p}$ value } \\
\hline & $\begin{array}{c}\text { Present } \\
(\%)\end{array}$ & $\begin{array}{c}\text { Absent } \\
(\%)\end{array}$ & \\
\hline \multicolumn{4}{|l|}{ Age (Years) } \\
\hline$\leq 35$ & 9.1 & 0.0 & \\
\hline $36-45$ & 9.1 & 14.3 & \\
\hline $46-55$ & 27.3 & 14.3 & \\
\hline $56-65$ & 45.5 & 57.1 & \\
\hline$>65$ & 9.1 & 14.3 & \\
\hline \multicolumn{4}{|l|}{ Comorbidity } \\
\hline Hypertension & 81.8 & 85.7 & 0.999 \\
\hline Diabetes mellitus & 18.2 & 0.0 & 0.141 \\
\hline Ischemic heart disease & 9.1 & 0.0 & 0.511 \\
\hline History of previous stroke & 54.5 & 14.3 & 0.016 \\
\hline
\end{tabular}

Table II

Distribution of $\mathrm{mRS}$ scale in presence of collateralization

\begin{tabular}{|lrrrrrr|}
\hline mRS & \multicolumn{3}{c}{ Collateralization } & \multicolumn{4}{c|}{ Without collateralization } \\
\cline { 2 - 7 } & $\begin{array}{r}\text { Day 1 of } \\
\text { stroke }\end{array}$ & $\begin{array}{r}\text { 3 months } \\
\text { after stroke }\end{array}$ & $\begin{array}{r}\text { ap } \\
\text { value }\end{array}$ & $\begin{array}{r}\text { Day 1 of } \\
\text { stroke }\end{array}$ & $\begin{array}{r}3 \text { months } \\
\text { after stroke }\end{array}$ & $\begin{array}{r}{ }^{\text {ap }} \text { value } \\
\text { vale }\end{array}$ \\
\hline$>2$ & 45.5 & 9.1 & 0.008 & 71.4 & 14.3 & 0.008 \\
$<2$ & 54.5 & 90.9 & \multicolumn{5}{c}{28.6} & 85.7 & \\
aMcNemar test was done to measure the level of significance & \\
\hline
\end{tabular}

ce on subsequent stroke characteristics.

The objectives of the study was to see the prognosis of ischemic stroke patients due to collateralization after unilateral or bilateral carotid stenosis.

\section{Materials and Methods}

This study was done on the ischemic stroke patients admitted in the inpatient Department from March 2017 to March 2018. Digital subtraction angiography was done in the catheter laboratory. From the report, information regarding completeness of circle of Willis and details of collateralization were obtained according to the specified objectives. The severity of the stroke was assessed by mRS scale first at the time of registration and after three months.

mRS score of the patients of ischemic stroke who had carotid stenosis were compared between the groups with collateralization and without collateralization. mRS scale of $<2$ was categorized as normal and $\mathrm{mRS}$ scale $>2$ was categorized as disease or disable.

\section{Statistical analysis}

The difference of disability between the groups was tested by McNemar test.

\section{Results}

Table I shows that the most frequent age group was 56-65 years representing $45.5 \%$ who developed collateralization after stroke but $57.1 \%$ was not developed.

Table I shows that $81.8 \%$ stroke patients developed collateralization but $85.7 \%$ not, who also suffered from hypertension. It was not statistically significant. But patients who had history of previous stroke, $54.5 \%$ patients developed collateralization which was statistically significant $(\mathrm{p}<0.05)$.

Table II shows that stroke patients who developed collateralization, $90.9 \%$ patients $\mathrm{mRS}$ scale improveed $(<2)$ after three months. It was statistically significant $(p>0.05)$. The stroke patients who did not develop collateralization, $85.7 \%$ mRS scale improved $(<2)$. It was statistically significant.

\section{Discussion}

In this study, the most frequent age group was 5665 years. Among them, 45.5\% developed collateralization after stroke, though it was not statistically significant. One study showed older age group (mean age $66.9 \pm 11.6$ years) developed less collateral.10 In this study, $81.8 \%$ stroke patients developed 
collateralization, who also suffered from hypertension. It was not statistically significant. Another study showed $66 \%$ developed good collateral who were hypertensive.11 Previously one study found $64.5 \%$ patients who were hypertensive developed collateralization after carotid occlusion.12 Patients who were previously diabetic and suffered from stroke with carotid stenosis, $18 \%$ patients were developed collateralization. One study found, collateralization development was $36 \% .11$ In this study, patients who had history of previous stroke, $54.5 \%$ patients developed collateralization which was statistically significant. One study showed $78 \%$ patients developed good collateral who had recurrent stroke. $\underline{11}$

Circle of Willis was found to be incomplete in $77.8 \%$ patients. In a study in Pakistani population found circle of Willis is incomplete in $33.5 \%$ of individuals. $\underline{13}$

Another study previously showed $52 \%$ patients had incomplete circle of willis $\underline{14}$ This finding was not correlated with the previous study, because in the study cerebral DSA was done only in selected cases who had carotid stenosis. mRS score of the patient of ischemic stroke who had carotid stenosis was compared between groups with collateralization and without collateralization. In this study, mRS scale of $<2$ was categorized as normal and mRS scale $>2$ was categorized as diseased or disable. In this study, stroke patients with carotid stenosis, who developed collateralization, $90.9 \%$ patients mRS scale improved $(<2)$ after three months. It was statistically significant. Previously one study showed only $12 \%$ patients with poor collateral compensation resulting in less favorable outcome.11 About $88 \%$ patients who had preserved good collateral compensation in patients with compromised antegrade flow was associated with more favorable outcome. This adds to the growing evidence of prognostication role by collateral circulation flow, associated with more favorable outcome (OR 7.50, 95\% CI 1.11-50.7, p=0.04). $.15-17$ This study suggests that composite antegrade and collateral assessment is feasible and useful in the prognostication of patients with chronic carotid stenosis. Some study previously showed leptomeningeal collateral play an important role after ischemic stroke and results in good outcome.1 Even in acute stroke patients good outcome was found after revascularization in presence of good collateral.6,9 One study found infarct volume was depended on collateral. 19 The effect of corticocortical collateralization was evaluated on the prognosis of stroke. In case of proximal and distal intracranial stenosis of internal carotid artery, outcome depends on collateralizations.7,12, 14, 20,21 Prognosis was not significantly associated with antegrade or collateral grade per se.11 The favorable neurological outcomes among patients with good collateral compensation could be linked to the neuroplasticity theory. Neuroplasticity in poststroke by synaptogenesis or dendritic arborization. $\underline{22}$ An animal model demonstrated restoration of perfusion to ischemic borders by collateral circulation via arterioles and new capillaries in Wistar rats after surgical ligation of MCA branches. $\underline{23}$ Collateral circulation potentially provides blood supply to the perilesional brain parenchyma to facilitate repair and recovery, and may partially explain why patients with good collateral flow had better neurological recovery. $\underline{24}$

\section{Conclusion}

Carotid stenosed patients who suffered from ischemic stroke, improved to some extent whether collateralization developed among major vessels or not.

\section{Ethical Issue}

The study was approved by the institutional review board of Bangabandhu Sheikh Mujib Medical University IRB Ref No. Bsmmu/2016.1598, Date: 17.11.2016. The patients informed written consent was taken from each patient.

\section{Acknowledgement}

The study was funded by the Bangabandhu Sheikh Mujib Medical University research grant. Ref No. BSMMU/2017/2618(28). Date: 14.03.2017.

\section{References}

1. Miralles M, Dolz JL, Cotillas J, Aldoma J, Santiso M A, Gimenez A. The role of the circle of Willis in carotid occlusion: Assessment with phase contrast MR angiography and transcranial duplex. Eur J Vasc Endovasc Surg. 2000; 10: 424-30.

2. Henderson RD, Eliasziw M, Fox AJ, Rothwell PM, Barnett HJ. Angiographically defined collateral circulation and risk of stroke in patients with severe carotid artery stenosis. North American Symptomatic Carotid Endarterectomy Trial (NASCET) Group. Stroke 2000; 31: 128-32.

3. Naveen SR, Bhat V, Karthik GA. Magnetic resonance angiographic evaluation of circle of Willis: A morphologic study in a tertiary hospital set up. Ann Indian Acad Neurol. 2015; 18: 391-97.

4. Alpers BJ, Berry RG, Paddison RM. Anatomical studies of the circle of Willis in normal brain. Am Med Assoc Arch Neurol Psychiatry. 1959; 81: 40918.

5. Brozici M, van der Zwan A, Hillen B. Anatomy and functionality of leptomeningeal anastomoses: A 
review. Stroke 2003; 34: 2750-62.

6. Maas MB, Lev MH, Ay H, Singhal AB, Greer DM Smith WS, Harris GJ, Halpern E, Kemmling A, Koroshetz WJ, et al. Collateral vessels on CT angiography predict outcome in acute ischemic stroke. Stroke 2009; 40: 3001-05.

7. Lima FO, Furie KL, Silva GS, Lev MH, Camargo EC, Singhal AB, Harris GJ, Halpern EF, Koroshetz WJ, Smith WS, et al. The pattern of leptomeningeal collaterals on CT angiography is a strong predictor of long-term functional outcome in stroke patients with large vessel intracranial occlusion. Stroke 2010; 41: 2316-22.

8. McVerry F, Liebeskind DS, Muir KW. Systematic review of methods for assessing leptomeningeal collateral flow. Am J Neuroradiol. 2012; 33: 576-82.

9. Kim JT, Park MS, Choi KH, Nam TS, Choi SM, Cho $\mathrm{KH}$. Clinical implications of collateral middle cerebral artery flow in acute ischaemic stroke with internal carotid artery occlusion. Eur J Neurol. 2011; 18: $1384-90$

10. Menon BK, Smith EE, Coutts SB, Welsh DG, Faber JE, Goyal M, Hill MD, Demchuk AM, Damani Z, Cho KH, Chang HW, Hong JH, Sohn SI. Leptomeningeal collaterals are associated with modifiable metabolic risk factors. Ann Neurol. 2013; 74: 241-48.

11. Lau AY, Wong EH, Wong A, Mok VC, Leung TW, Wong KS. Significance of good collateral compensation in symptomatic intracranial atherosclerosis. Cerebrovasc Dis. 2012; 33: 517-24.

12. Wufuer A, Mijiti P, Abudusalamu R, Dengfeng H, Jian C, Jianhua M, Xiaoning Z. Blood pressure and collateral circulation in acute ischemic stroke. Herz. 2018: 2018.

13. Siddiqi H, Tahir M, Lone KP. Variations in cerebral arterial circle of Willis in adult Pakistani population. J Coll Phys Surg Pakistan. 2013; 23: 615-19.

14. Iqbal S. A comprehensive study of the anatomical variations of the circle of Willis in adult human brains. J Clin Diagn Res. 2013; 7: 2423-27.
15. Shuaib A, Butcher K, Mohammad AA, Saqqur M, Liebeskind DS. Collateral blood vessels in acute ischaemic stroke: A potential therapeutic target. Lancet Neurol. 2011; 10: 909-21.

16. Liebeskind DS, Cotsonis GA, Saver JL, Lynn MJ, Cloft HJ, Chimowitz MI. Collateral circulation in symptomatic intracranial atherosclerosis. J Cereb Blood Flow Metab. 2010; 31: 1293-301.

17. Brunser AM, Lavados PM, Carcamo DA, Hoppe A, Olavarria V, Diaz V, Rivas R. Additional information given to a multimodal imaging stroke protocol by transcranial doppler ultrasound in the emergency room: A prospective observational study. Cerebrovasc Dis. 2010; 30: 260-66.

18. Brozici M, van der Zwan A, Hillen B. Anatomy and functionality of leptomeningeal anastomoses: A review. Stroke 2003; 34: 2750-62.

19. Marks MP, Lansberg MG, Mlynash M, Olivot JM, Straka M, Kemp S, McTaggart R, Inoue M, Zaharchuk G, Bammer R, Albers GW. Effect of collateral blood flow on patients undergoing endovascular therapy for acute ischemic stroke. Stroke 2014; 45: 1035-39.

20. Liebeskind DS, Cotsonis GA, Saver JL, Lynn MJ, Turan TN, Cloft HJ, Chimowitz MI. Collaterals dramatically alter stroke risk in intracranial atherosclerosis. Ann Neurol. 2011; 69: 963-74.

21. Mangiafico S, Saia V, Nencini P, Romani I, Palumbo V, Pracucci G, Consoli A, Rosi A, Renieri L, Nappini S, Limbucci N, Inzitari D, Gensini GF. Effect of the interaction between recanalization and collateral circulation on functional outcome in acute ischaemic stroke. Int Neuroradiol. 2014; 20: 704-14.

22. Rossini PM, Calautti C, Pauri F, Baron JC. Poststroke plastic reorganisation in the adult brain. Lancet Neurol. 2003; 2: 493-502.

23. Wei L, Erinjeri JP, Rovainen CM, Woolsey TA. Collateral growth and angiogenesis around cortical stroke. Stroke 2001; 32: 2179-84.

24. Han JH, Wong KS. Is counterpulsation a potential therapy for ischemic stroke? Cerebrovasc Dis. 2008; 26: 97-105. 